\title{
Theoretical Insight into the Mechanism of an Efficient L-Proline-catalyzed Transamidation of Acetamide with Benzylamine
}

\author{
Weirong $\mathbf{W u}^{\dagger, \$}$ \\ ${ }^{\dagger}$ Key Laboratory of Inorganic Chemistry in Universities of Shandong, Department of Chemistry and Chemical Engineering, \\ Jining University, Qufu 273155, Shandong, China \\ :School of Chemistry and Chemical Engineering, Jinan University, Jinan 250022, China. E-mail: wuweirong011@163.com \\ Received February 3, 2014, Accepted May 11, 2014
}

\begin{abstract}
The detailed mechanisms of the efficient L-proline and pyrrolidine catalyzed transamidation of acetamide with benzylamine have been investigated using density functional theory (DFT) calculations. Our calculated results show: (1) the mechanisms of two catalytic cycle reactions are similar. However, the rate-determining steps of their reactions are different for the whole catalytic process. One is the intramolecular nucleophilic addition reaction of 1-COM, the other is hydrolysis reaction of 2-C. (2) $\mathrm{COOH}$ group of L-proline is essential for efficient transamidation. The computational results are in good agreement withthe experiment finding and mechanism resported by Rao et al. for L-proline-catalyzed synthesis of amidesin good to excellent yields.
\end{abstract}

Key Words : Transamidation, L-Proline-catalydst, Pyrrolidine-catalydst, Acetamide, Benzylamine

\section{Introduction}

The amide bond is arguably one of the most important gifts in nature, as it is essential to sustain living system and exits in all natural peptides and protein structures. ${ }^{1}$ Amides are also often used as synthetic intermediates for the preparation of natural products, pharmaceuticals molecules, agrochemicals, polymers, etc. ${ }^{2,3}$ Amides are surprisingly robust compared to their related derivatives due to the structural characteristics of amide bonds. Therefore, there has bee$\mathrm{n}$ much effort aimed at the development of efficient syntheticmethodologies for improving the preparation of amides. In general, amides are prepared by the coupling of amines with carboxamides, alcohols, ${ }^{4}$ aldehydes,${ }^{5}$ carboxylic acid derivatives ${ }^{6}$ etc., or by the reaction of primary amides with aryl and alkyl halides. ${ }^{7}$ Alternatively, the transamidation process is an attractive tool in the field of synthetic organic chemistry and represents an excellent unusual route for the functionalization of a given carboxamide. ${ }^{8}$ So far, elegant methods for transamidation reactions (i.e., transamidation processes catalyzed by copper, ${ }^{9}$ cerium, ${ }^{10}$ hydroxylamine hydrochloride, ${ }^{11}$ ammonium bromide, ${ }^{12}$ and boric acid, ${ }^{13}$ hypervalent iodine $^{14}$ ) have been reported. Unfortunately, these methods to accomplish the desired amide exchange process suffer from certain demerits ${ }^{2}$ (i.e. the excessive use of an expensive or waste-generating activation reagents, reversible reactions giving mixtures of amides). In view of environmental friendliness, it is desirable to develop benign and metal-free transamidation procedures with high yield and selectivity. ${ }^{15}$

Recently, Rao and his co-workers ${ }^{16}$ reported a novel solvent-free L-proline-catalyzed transamidation of carboxamides and amines. In their experiment, acetamide and benzylamine were selected as a model system. In the presence of L-proline (1-L) (10 mol \%), the reaction was carried out in a sealed tube at $100{ }^{\circ} \mathrm{C}$ for $36 \mathrm{~h}$ and proceeded smoothly to lead to the formation of the desired transamidation product $\mathrm{P}$ in $99 \%$ yield. When the reaction was performed in the pyrrolidine (2-L) $(10 \mathrm{~mol} \%)$, an $10 \%$ conversion was observed (see Scheme 1). They concluded the L-proline is inexpensive, readily available and conveniently. What's more, it could be efficiently applied to transamidation of a wide range of amines containing benzylic, aromatic, aliphatic, propargylic, and heteroaromatic. The proposed mechanism by Rao is shown in Scheme 2.

To the best of our knowledge, there are no theoretical studies for the mechanism of the L-proline catalyzed transamidation process reported by Rao et al. Hence, we report a thorough density functional theory (DFT) computational investigation on the mechanisms of the L-proline and pyrrolidine-catalyzed transamidation of acetamide (R1) with benzylamine (R2) based on the experimental evidence reported by Rao et al. In the present study, our aim is to understand the mechanism details of the reactions at the molecular level by providing the geometric and energetic information of the intermediates and transition states involved.

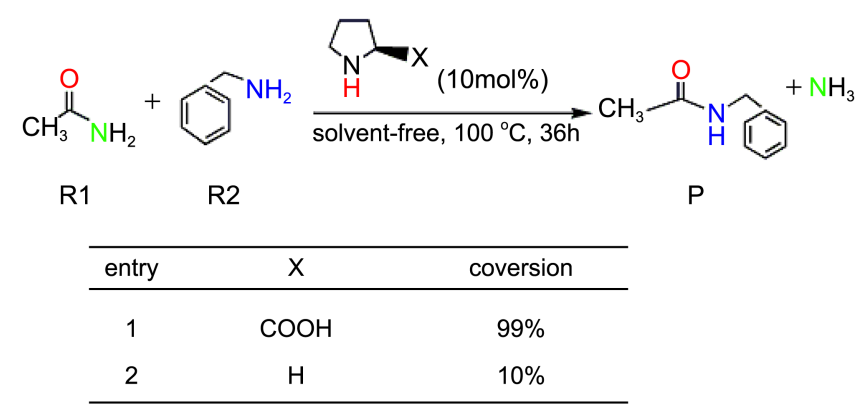

Scheme 1. Rao's L-proline and pyrrolidine-catalyzed transamidation of acetamide with benzylamine. 


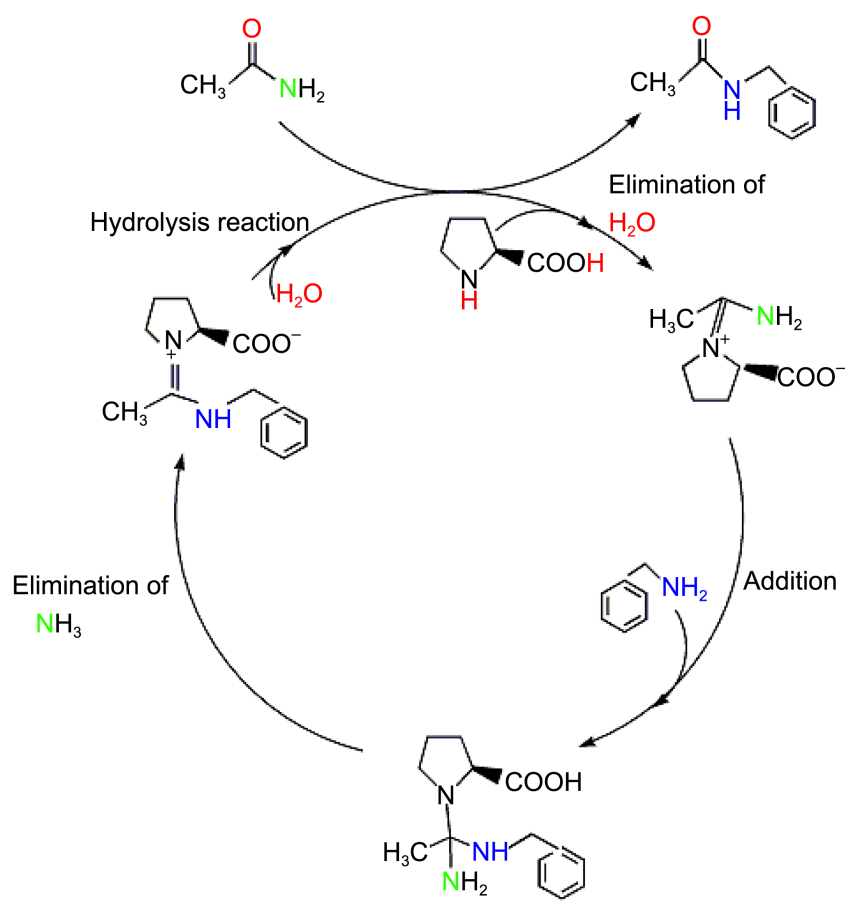

Scheme 2. Sketch of the catalytic cycle for the transamidation of acetamide with benzylamine.

\section{Computation Methods}

All the calculations were performed using the Gaussian 03 program package. ${ }^{17}$ The geometries of the reactants, complex, intermediates, products and transition states were fully optimized by hybrid density functional theory (DFT) ${ }^{18-20}$ using the $6-31 \mathrm{~g}(\mathrm{~d}, \mathrm{p})^{21}$ basis set. This hybrid DFT method has generally been shown to perform quite well in the mechanistic studies of transition metal-or non-transition metalcatalyzed reactions. ${ }^{22}$ The $6-31 \mathrm{G}(\mathrm{d}, \mathrm{p})$ basis set has been popularly used in the mechanistic studies of Au-catalyzed reactions and is shown to be quite reliable for optimizing both the geometries and energies. ${ }^{23}$ Vibrational frequencies calculated were used to further identify all of the stationary points as minima (intermediates (zero imaginary frequencies) or transition states (one imaginary frequencies)), zero-point energy (ZPE). The calculations of intrinsic reaction coordinate $(\mathrm{IRC})^{24}$ were performed to further confirm that the transition states connect between designated intermediates. The relative energies were thus corrected for the vibrational zero-point energies (ZPE, not scaled). In order to obtain more reliable energies of various structures, the B3LYP/6$31 \mathrm{G}(\mathrm{d}, \mathrm{p})$ optimized geometries were used for single-point calculations at MP2 $2^{25} / 6-31 \mathrm{~g}(\mathrm{~d}, \mathrm{p})$ level. Therefore, we expect that the MP2//B3LYP calculations reported in this work are reliable.

\section{Results and Discussion}

In this sections, we present the calculated results for transamidation reaction of acetamide (R1) with benzylamine
(R2) catalyzed by the L-proline and pyrrolidine according to the proposed catalytic cycle shown in Scheme 2, respectively.

The Transamidation Reaction Catalyzed by L-Proline. We first discuss the mechanism of L-proline-catalyzed transamidation reaction of R1 with R2. The optimized geometries with selected key geometry parameters for the reactants, complex, intermediates, transition states and product $(\mathrm{P})$ are given in Figure 1. The potential energy surface profiles for the transamidation reaction are depicted in Figure 2. It should be noted that the energy of R1 + L-proline (1-L) is set at zero as a reference for other species.

From the energy profile we can find the first step of this mechanism starts from the L-proline (1-L) catalyst approaching to one of the reactants (R1), forming a weakly-bound complex 1-COM $(-5.71 \mathrm{kcal} / \mathrm{mol}, \Delta \mathrm{E})$, which is lower than the reactants $(\mathrm{R} 1+1-\mathrm{L})$. Subsequently, there is nucleophilic attack of $\mathrm{N}^{1}$ - atom of the L-proline (1-L) on the positively charged $\mathrm{C}^{9}$ - atom of $\mathrm{R} 1$ to lead to the formation of the intermediate $1-\mathrm{IM}(-0.16 \mathrm{kacl} / \mathrm{mol})$ via surmounting a 38.24 $\mathrm{kcal} / \mathrm{mol}$ energy barrier, transition states $1-\mathrm{TS} 1$ (32.53 kcal/ $\mathrm{mol})$. During the process of generating 1-IM, the distance $\mathrm{N}^{1}-\mathrm{C}^{9}$ is gradually shorten. As shown in Figure 1, the distances $\mathrm{N}^{1}-\mathrm{C}^{9}$ in 1-COM, 1-TS1 and 1-IM is $3.664 \AA$, $1.695 \AA$ and $1.458 \AA$, respectively. Furthermore, the $\mathrm{C}^{9}-\mathrm{O}^{1}$ bond gradually strenches and losts its double bond character (1-COM: $1.230 \AA, 1-T S: 1.343 \AA, 1-I M: 1.434 \AA$ ). The fact that is L-proline (1-L) catalyst shows some activity and is sufficiently efficient. And at the same time, the $\mathrm{H}^{1}$ atom is migrating from the $\mathrm{N}^{1}$ to $\mathrm{O}^{1}$. From the intermediate 1-IM, there are two different reaction pathway a and $b$, both of which involve in different intramolecular H-migration reactions.

In the pathway a, the $1-\mathrm{IM}(-0.16 \mathrm{kcal} / \mathrm{mol})$ firstly isomerizes to another intermediate $1-\mathrm{IM}^{*}(4.44 \mathrm{kcal} / \mathrm{mol})$ for dehydration. And then, the $1-\mathrm{IM}^{*}$ transforms to intermediate $1-\mathrm{A}(3.09 \mathrm{kcal} / \mathrm{mol})$ via $1-\mathrm{TS} 2(16.16 \mathrm{kcal} / \mathrm{mol})$ by the elimination of $\mathrm{H}_{2} \mathrm{O}$ molecular with a barrier of $11.72 \mathrm{kcal} /$ mol, followed by a conjugated $\Pi$-bond $(\mathrm{N}-\mathrm{C}-\mathrm{N})$ forming, which makes $1-\mathrm{A}$ lie only $3.25 \mathrm{kcal} / \mathrm{mol}$ above the 1 -IM. It should be noted that the intermediate 1-IM lies lower than that of $1-\mathrm{IM}^{*}$. In $1-\mathrm{IM}^{*}$, it is evident that the $\mathrm{N}^{1}-\mathrm{C}^{9}$ is significantly stronger than that of 1-IM as demonstrated by their bond lengths of 1.425 and $1.458 \AA$, respectively. This can give a good explanation of the intermediation $1-\mathrm{IM}^{*}$ lies 4.6 $\mathrm{kcal} / \mathrm{mol}$ above $1-\mathrm{IM}$.

On the other hand, as shown in the pathway b of Figure 2. 1-IM converts to 1-A though another transition state 1-TS2* $(50.08 \mathrm{kcal} / \mathrm{mol})$. In $1-\mathrm{TS} 2 *$, The $\mathrm{H}^{3}$ atom is migrating from $\mathrm{N}^{2}$ to $\mathrm{O}^{1}$. The $\mathrm{N}^{2}-\mathrm{H}^{3}$ and $\mathrm{H}^{3}-\mathrm{O}^{1}$ bones are $1.139 \AA$ and 1.449 $\AA$, respectively. The energy barrier of this process is 50.24 $\mathrm{kcal} / \mathrm{mol}$. By comparing the $\mathrm{H}$ - atom migrations of 1-TS2 with $1-\mathrm{TS} 2 *$ in Figure 1, one can find the energy barrier of pathway a is obviously different from that of pathway $b$. This may be due to different ability of the $\mathrm{H}$ atom donors, $\mathrm{COOH}$ and $\mathrm{NH}_{2}$ group. According to the difference of the two energy barrier heights, we can rule out the pathway $b$ is not the best path. 


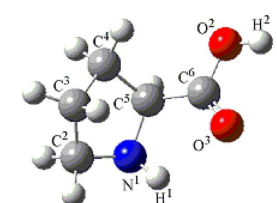

1-L-Proline

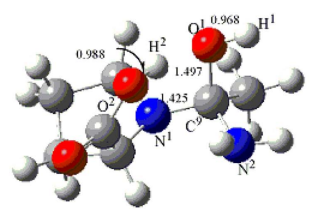

$1-\mathrm{IM}^{*}$

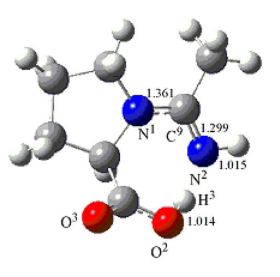

$1-\mathrm{A}$

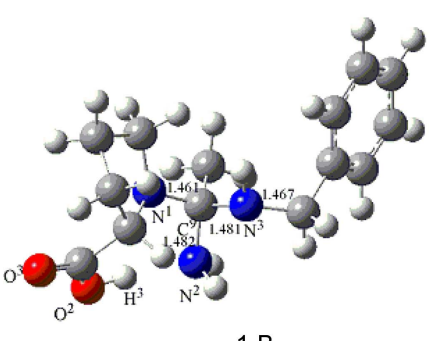

1-B
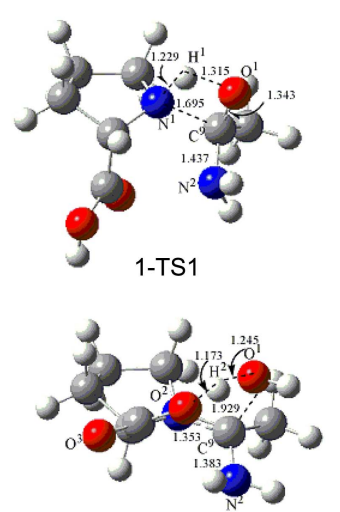

1-TS2
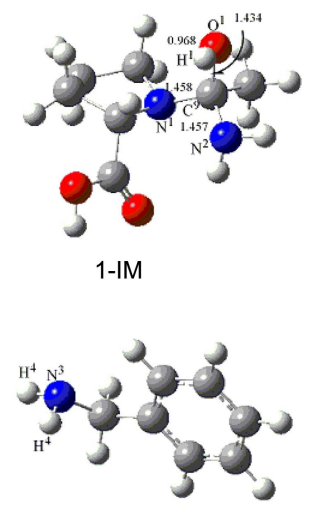

$\mathrm{R} 2$

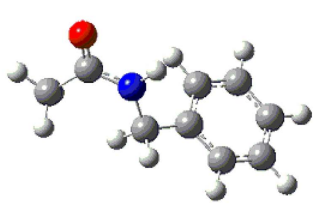

$P$

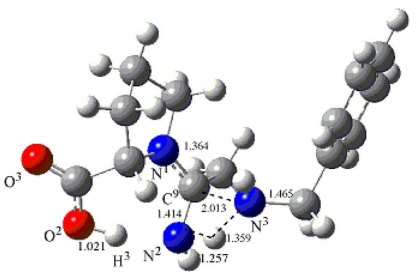

1-TS3

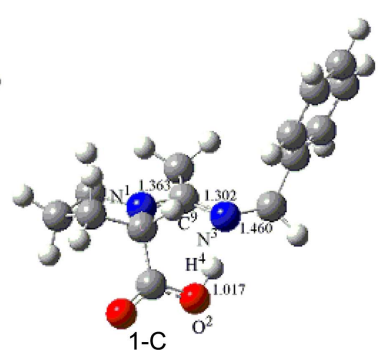

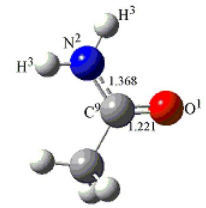

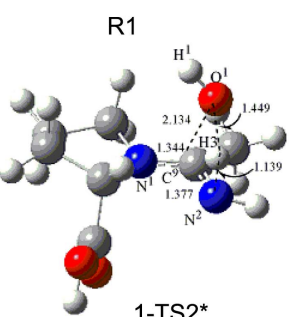

1-TS2*

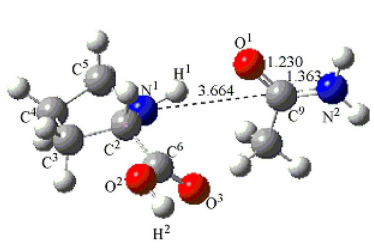

1-COM

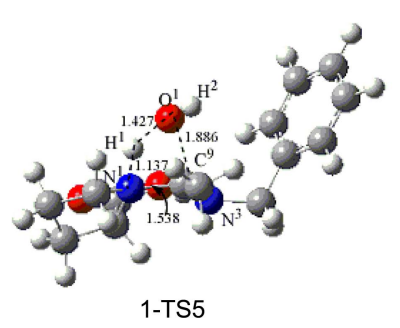

Figure 1. Optimized structures for the species involved in the L-proline-catalyzed (1-L) transamidation of acetamide with benzylamine. Bond distance are given in $\AA$.

The nucleophilic attack of $\mathrm{N}^{3}$ - atom of another reactants (R2) on the positively charged $\mathrm{C}^{9}$ of 1-A leads to the formation of a new intermediate 1-B through 1-TS3. The formation of 1-B is an exothermic process (The energy of reaction for the $1-\mathrm{B}$ was $-5.63 \mathrm{kcal} / \mathrm{mol}$ with respect to $1-\mathrm{A}$, as shown in Figure 2). The activation energy of this step is $35.0 \mathrm{kcal} / \mathrm{mol}$. Subsequently, 1-B can evolve into 1-C via 1TS4, a transition state of the $\mathrm{NH}_{3}$ molecular elimination. From the optimized geometrical parameters of 1-TS4, it is apparent that $\mathrm{H}^{3}$ atom is moving from $\mathrm{O}^{2}$ to $\mathrm{N}^{2}$ atom. As shown in Figure 2, the energy barriers of the process is 12.91 $\mathrm{kcal} / \mathrm{mol}$ and the formation of 1-C is an endothermic process (The energy of reaction for the $1-\mathrm{C}$ was $2.03 \mathrm{kcal} / \mathrm{mol}$ with respect to 1-B, as shown in Figure 2). In $1-\mathrm{C}$, the $\mathrm{N}^{1}-\mathrm{C}^{9}$ and $\mathrm{N}^{3}-\mathrm{C}^{9}$ bonds are shorten to $1.363 \AA$ and $1.302 \AA$, respectively. Clearly, the $\mathrm{N}^{3}-\mathrm{C}^{9}$ bond becomes double bond again and the length of the $\mathrm{N}^{1}-\mathrm{C}^{9}$ bond between single and double bonds. There is subsequent hydrolysis reaction of 1-C to result in the formation of the desired product $\mathrm{P}(-5.30 \mathrm{kcal} /$ mol, lower than reactants $(\mathrm{R} 1+1-\mathrm{L}))$ and regeneration of the catalyst (1-L) through 1-TS5. Figure 2 shows that the energy barrier of this step $(1-\mathrm{C} \rightarrow 1-\mathrm{TS} 5 \rightarrow \mathrm{P})$ is calculated to be
$35.55 \mathrm{kcal} / \mathrm{mol}$. This process is exothermic by $4.79 \mathrm{kcal} /$ mol. In total, the whole catalytic process is exothermic by $-5.30 \mathrm{kcal} / \mathrm{mol}$, lower than reactants $(\mathrm{R} 1+1-\mathrm{L})$. It is clear that the intramolecular nucleophilic addition reaction of 1COM is unfavorable kinetically. Notably, this step is ratedetermining for the whole catalytic process.

According to the Figure 2, it can be directly seen that there are two key energy-demanding steps in the catalytic cycle reaction. One is the intramolecular nucleophilic addition reaction of 1-COM via 1-TS1 with a barrier of $38.24 \mathrm{kcal} /$ mol. The other is the hydrolysis reaction of $1-\mathrm{C}$ with a barrier of $35.55 \mathrm{kcal} / \mathrm{mol}$. It is the reason why the experimental was carried out at a higher temperature $\left(100{ }^{\circ} \mathrm{C}\right)$ for $36 \mathrm{~h}$. Futhermore, the energy barriers of the two steps labeled with the blue line $(11.72 \mathrm{kcal} / \mathrm{mol}$ and $12.91 \mathrm{kcal} /$ mol, respectively) are very lower than other reaction steps in the Figure 2, indicating that $\mathrm{COOH}$ group of L-proline is essential for efficient transamidation, which is consistent with the experiment finding proposed by Rao et al.

The Transamidation Reaction Catalyzed by Pyrrolidine. Then, we extend our study to the transamidation reaction catalyzed by pyrrolidine (2-L) (see Scheme 1). The calculated 


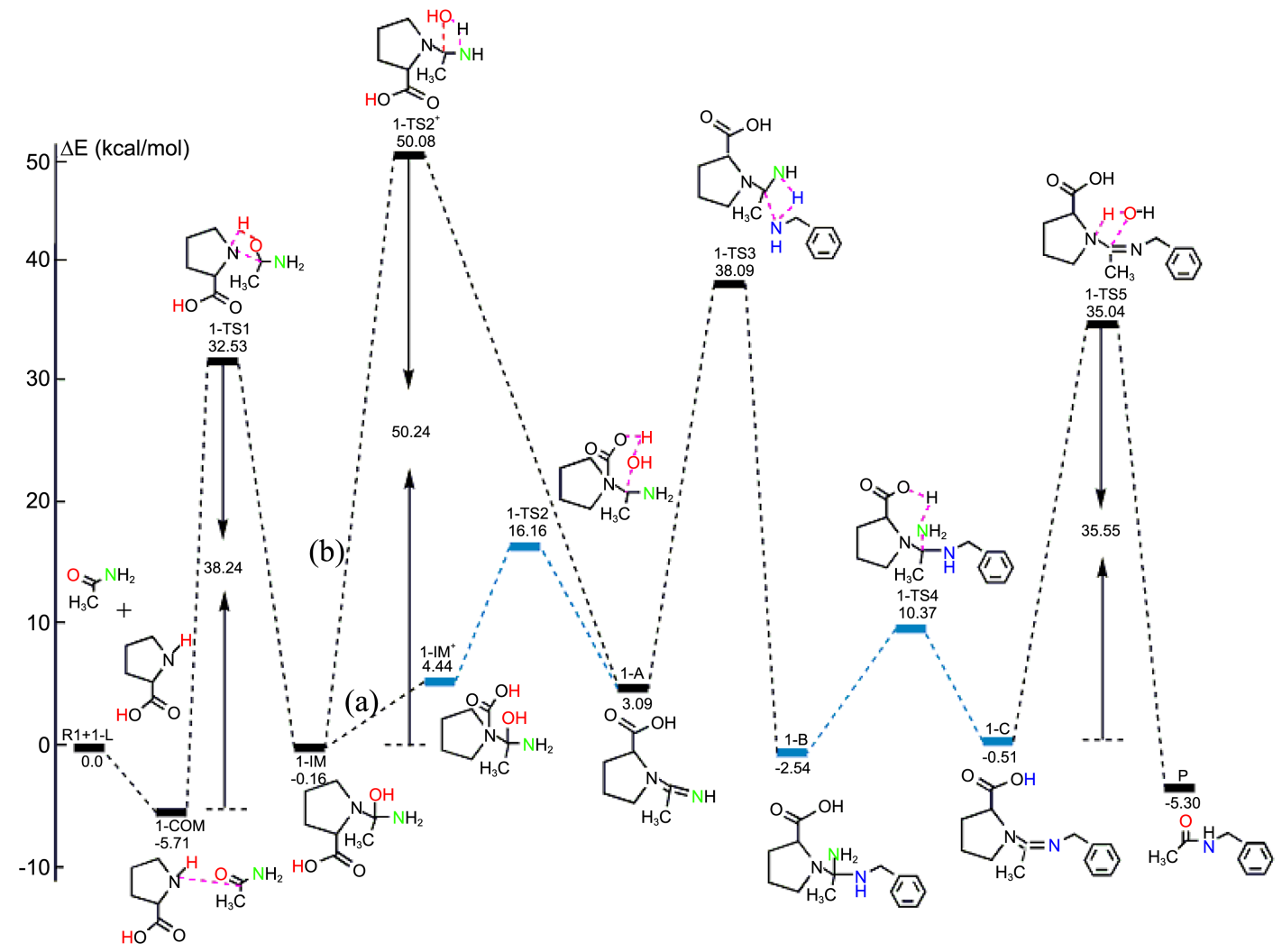

Figure 2. The potential energy surface (PES) for L-proline-catalyzed transamidation reaction of acetamide and benzylamine with MP2/6$31 \mathrm{G}(\mathrm{d}, \mathrm{p})$.

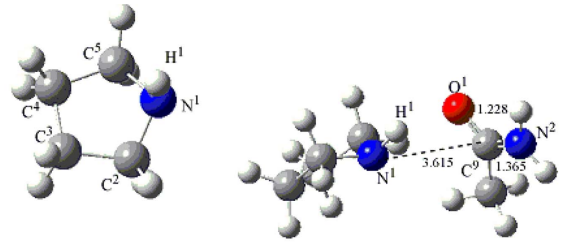

Pyrrolidine (2-1)

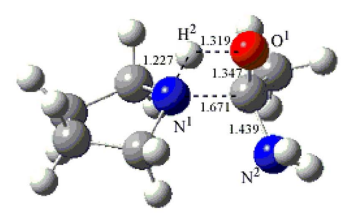

2-TS1

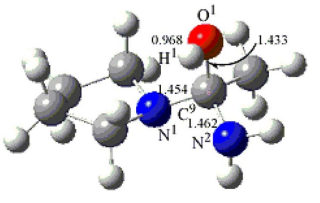

2-IM

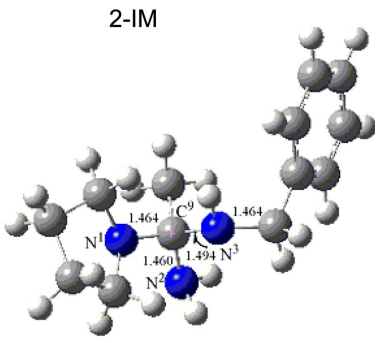

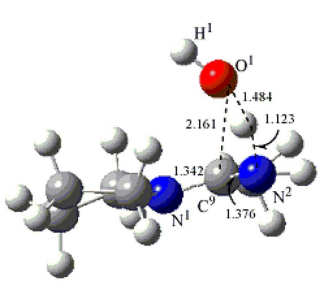

2-TS2

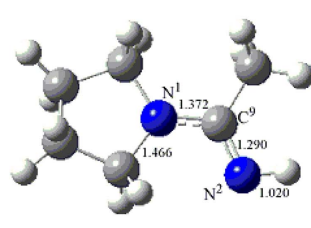

2-A

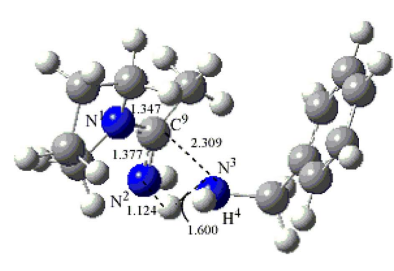

2-TS3

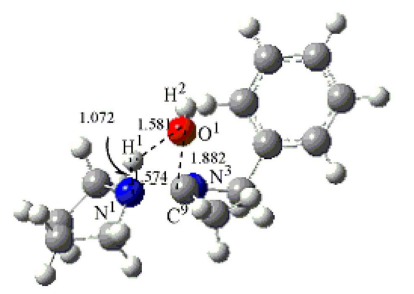

2-TS5

Figure 3. Optimized structures for the species involved in the transamidation reaction catalyzed by pyrrolidine (2-L) of acetamide with benzylamine. Bond distance are given in $\AA$. 


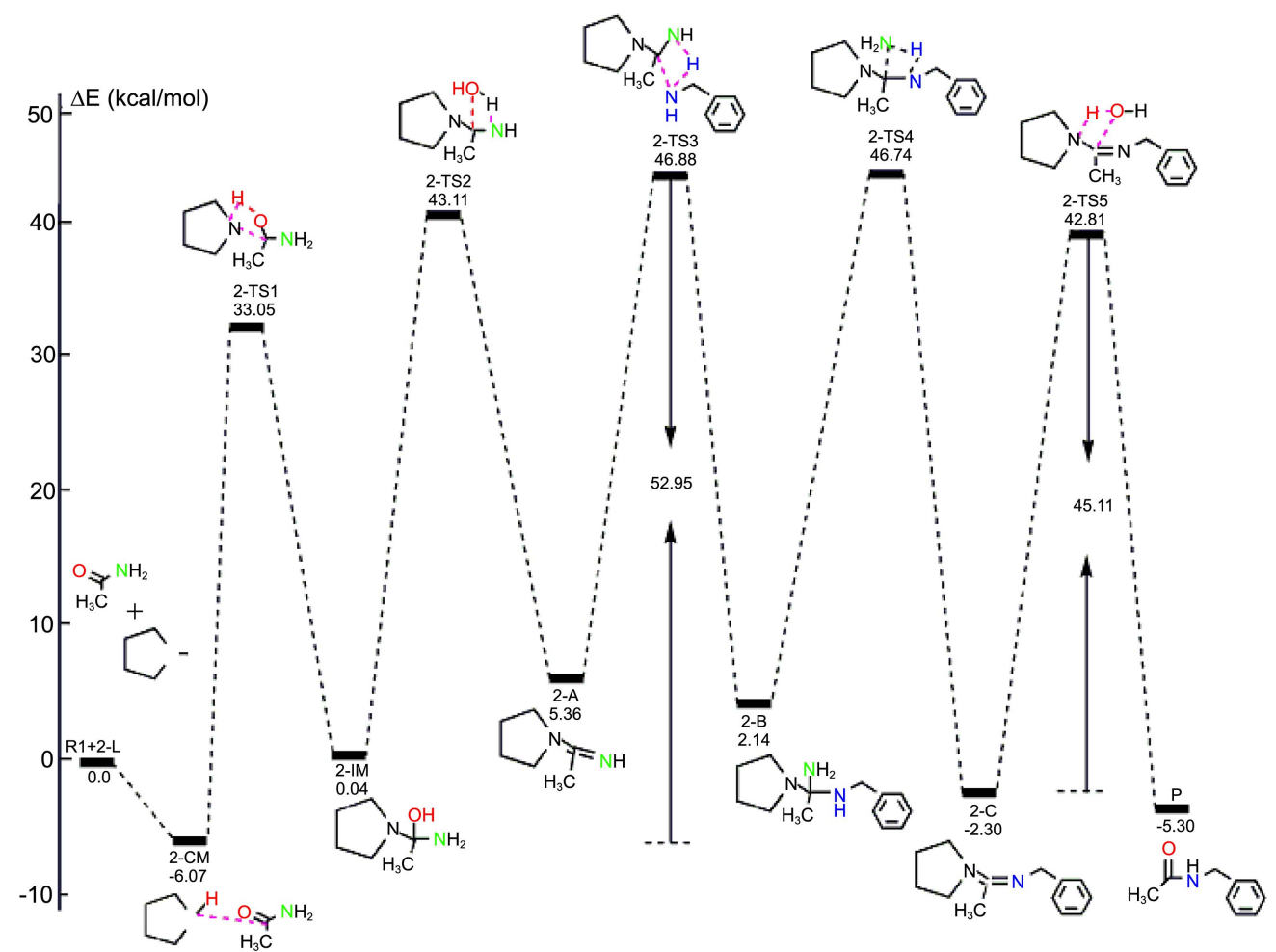

Figure 4. Potential energy surface of pyrrolidine-catalyzed (2-L) transamidation reaction of acetamide and benzylamine with MP2/6-31G (d, p).

mechanism detail is very similar to the those discussed above, so we only describe the catalytic cycle and the relative energy surface profile briefly. The optimized geometries with selected key geometry parameters are depicted in Figure 3. The calculated relative energy surface profiles are given in Figure 4. Note that the energy of R1 + pyrrolidine (2-L) is set at zero as a reference for other species.

At the entrance of the reaction, the reactants $(\mathrm{R} 1+2-\mathrm{L})$ firstly form a weakly-bound complex 2-COM though barrierfree exothermic reaction of $\Delta \mathrm{E}=6.07 \mathrm{kcal} / \mathrm{mol}$. Then, $\mathrm{COM}$ undergoes an intramolecular nucleophilic addition to form 2IM via 2-TS1 with a energy barrier of $39.12 \mathrm{kcal} / \mathrm{mol}$, which only higher $0.88 \mathrm{kcal} / \mathrm{mol}$ than the corresponding value to form 1-IM. After that, 2-IM will proceed with an intramolecular H-migration through 2-TS2 to 2-A. According to Figure 4, the barrier for the step of the forming 2-A is 43.07 $\mathrm{kcal} / \mathrm{mol}$, which is much higher than the corresponding value $(16.32 \mathrm{kcal} / \mathrm{mol})$ for the step of forming $1-\mathrm{A}$. In the following step, 2-A undertakes an intermolecular nucleophilic addition with R2 to form 2-B via 2-TS3. The energy of activation for this step is calculated to be $41.52 \mathrm{kcal} / \mathrm{mol}$ for 2-TS3. Moreover, the barriers to form 2-C through 2-TS4 with a second intramolecular H-migration is $44.60 \mathrm{kcal} / \mathrm{mol}$, which is much larger than the corresponding value (12.91 $\mathrm{kcal} / \mathrm{mol}$ ) for the step of forming 1-C. The barriers of the final step, hydrolysis reaction from $2-\mathrm{C}$ to final product $\mathrm{P}$, is $45.11 \mathrm{kcal} / \mathrm{mol}$. Clearly, the higher barrier calculated for 2TS5 indicates that this step is rate-determining for the whole catalytic process, and every step of the catalytic cycle reaction is high energy-demanding. But above all, the overall energy barrier of the catalytic reaction is calculated to be $52.95 \mathrm{kcal} / \mathrm{mol}$. That can explain the low conversion, the high temperature and rate of the pyrrolidine-catalyzed transamidation reaction of acetamide and benzylamine.

\section{Conclusion}

In summary, the mechanisms of the L-proline and pyrrolidine-catalyzed transmidation process of acetamide and benzylamine have been investigated by using DFT calculation. According to our calculations, the rate-determining steps of the two catalytic cycle reactions are different for the whole catalytic process although the mechanisms of both of the reactions is similar. The former is the intramolecular nucleophilic addition reaction of 1-COM via 1-TS1 with a barrier of $38.24 \mathrm{kcal} / \mathrm{mol}$. The latter is hydrolysis reaction of 2-C with a whole barrier of $45.11 \mathrm{kcal} / \mathrm{mol}$ and every step of its is high energy-demanding. This may be the reason why the conversion of the former is obviously higher than that of the latter. In addition, $\mathrm{COOH}$ group of L-proline is favored for efficient transamidation, which are consistent with the experimental observations of Rao et al.

Acknowledgments. This work was supported by National Natural Science Foundation of China (21303073) and the Youth Fund of Jining University (2013QNKJ03).

\section{References}

1. Atkinson, B. N.; Chhatwal, A. R.; Lomax, H. V.; Walton, J. W.; 
Williams, J. M. Chem. Commun. 2012, 11626.

2. Wang, G. W.; Yuan, T. T.; Li, D. D. Angew. Chem., Int. Ed. 2011, 50, 1380 .

3. Park, S. J.; Cho, C. G.; Lee, K. I. Bull. Korean Chem. Soc. 2004, 25,349 .

4. Zhang, M.; Imm, S.; Bähn, S.; Neumann, H.; Beller, M. Angew. Chem. 2011, 50, 11197.

5. Ghosh, S. C.; Ngiam, J. S. Y.; Seayad, A. M.; Tuan, D. T.; Chai, C. L.; Chen, A. J. Org. Chem. 2012, 77, 8007.

6. Charville, H.; Jackson, D.; Hodges, G.; Whiting, A. Chem. Commun. 2010, 1813.

7. Hartwig, J. F. Acc. Chem. Res. 2008, 41, 1534.

8. Allen, C. L.; Atkinson, B. N.; Williams, J. M. Angew. Chem. 2012, 124, 1412.

9. Zhang, M.; Imm, S.; Bähn, S.; Neubert, L.; Neumann, H.; Beller, M. Angew. Chem. 2012, 124, 3971.

10. Shimizu, Y.; Morimoto, H.; Zhang, M.; Ohshima, T. Angew. Chem., Int. Ed. 2012, 51, 8564.

11. Allen, C. L.; Atkinson, B. N.; Williams, J. M. Angew. Chem., Int. Ed. 2012, 51, 1383.

12. Tamura, M.; Tonomura, T.; Shimizu, K.-I.; Satsuma, A. Green
Chem. 2012, 14, 717.

13. Nguyen, T. B.; Sorres, J.; Tran, M. Q.; Ermolenko, L.; Almourabit, A. Org. Lett. 2012, 14, 3202.

14. Vanjari, R.; Allam, B. K.; Singh, K. N. RSC. Adv. 2013, 3, 1691.

15. Kappe, C. O.; Stadler, A.; Dallinger, D. Weinheim; Germany: Wiley-VCH Verlag GmbH \& Co. KgaA, 2012.

16. Rao, S. N.; Mohan, D. C.; Adimurthy, S. Org. Lett. 2013, 15, 1496.

17. Frisch, M. J.; Trucks, G. W.; Schlegel, H. B., et al., GAUSSIAN 03 (Revision E01); Gaussian Inc.: Pittsburgh PA, 2004.

18. Hohenberg, P.; Kohn, W. Phys. Rev. 1964, 136, B864.

19. Kohn, W.; Sham, L. J. Phys. Rev. 1965, 140, A1133.

20. Oh, D.; Choe, J. I. Bull. Korean Chem. Soc. 2007, 28, 596.

21. Rassolov, V. A. M.; Ratner, A. J.; Pople, A.; Redfern, P. C.; Curtiss, L. A. J. Comput. Chem. 2001, 22, 976.

22. Fang, R.; Ke, Z. F.; Shen, Y.; Zhao, C. Y.; Phillips, D. L. J. Org. Chem. 2007, 72, 5139.

23. Ando, K. J. Org. Chem. 2010, 75, 8516.

24. Gonzalez, C.; Schlegel, H. B. J. Chem. Phys. 1989, 90, 2154.

25. Curtis, L. A.; Raghavachari, K.; Pople, J. A. J. Chem. Phys. 1993, 98, 1293. 